\title{
INFLUÊNCIA DOS ELEMENTOS METEOROLÓGICOS NA EVAPOTRANSPIRAÇÃO DE REFERÊNCIA ESTIMADA UTILIZANDO-SE O IRRIGÂMETRO NO MUNICÍPIO DE GUANAMBI-BA
}

\author{
Cristiano Tagliaferre ${ }^{1}$, Alessandro de Paula ${ }^{2}$, Felizardo Adenilson Rocha ${ }^{3}$, William Viana Campos ${ }^{4}$, Diogo Ulisses \\ Guimarães $^{5}$
}

\section{RESUMO}

Existem poucos estudos sobre o comportamento e as interações dos elementos meteorológicos sobre a evaporação ou a evapotranspiração que ocorrem em evaporímetros como do Irrigâmetro. Sendo assim, objetivou-se com esse estudo analisar os efeitos das interações dos elementos meteorológicos, temperatura máxima e mínima do ar, umidade relativa do ar, velocidade do vento e radiação solar, na evapotranspiração de referência estimada utilizando-se o Irrigâmetro, operando em diferentes alturas do nível de água no evaporatório. O estudo foi conduzido na área experimental do Instituto Federal da Bahia, localizado no município de Guanambi-BA. O experimento foi montado em delineamento inteiramente casualizado com sete tratamentos e três repetições. Os tratamentos consistiram de Irrigâmetros equipados individualmente com evaporatórios operando com níveis de água de 1 a $7 \mathrm{~cm}$, tomados a partir de um nível de referência próprio do aparelho, totalizando 21 Irrigâmetros. Para avaliar os efeitos direto e indireto de cada variável meteorológica sobre a evapotranspiração de referência estimada pelo Irrigâmetro, utilizou-se a análise de trilha, que correlaciona a evapotranspiração, variável dependente, com os elementos meteorológicos, variáveis independentes. Em todos os níveis de água estudado o elemento meteorológico que apresentou maior correlação com a estimativa da evapotranspiração de referência foi a umidade relativa do ar, a radiação solar e a velocidade do vento, com valores iguais a 0,$58 ; 0,53$ e 0,49 , respectivamente.

Palavras-chave: Manejo da irrigação, coeficientes do irrigâmetro, análise de trilha.

\section{ABSTRACT \\ INFLUENCE OF METEOROLOGICAL EVAPOTRANSPIRATION IN REFERENCE ESTIMATED USING UP THE IRRIGAMETER IN THE MUNICIPALITY OF GUANAMBI-BA}

There are few studies on the behavior and interactions of meteorological elements on evaporation or evapotranspiration occurring in evaporimeters as the Irrigameter. Therefore, the aim of this study to analyze the effects of the interactions of weather elements, maximum temperature and minimum air, relative humidity, wind speed and solar radiation, the estimated reference evapotranspiration using the Irrigameter, operating in different heights of water level in evaporator. The study was conducted in the experimental area of the Federal Institute of Bahia, located in the municipality of Guanambi-BA. The experiment was a completely randomized design with seven treatments and three repetitions. The treatments were individually equipped with Irrigameters operating with equal water levels in the evaporators from 1 to $7 \mathrm{~cm}$, taken from a the reference level of the device, totaling 21 Irrigameters. To assess the direct and indirect effects of each meteorological variable on the reference evapotranspiration estimated by Irrigameter, the path analysis was used which correlates evapotranspiration, the dependent variable, with meteorological elements, the independent variables. In all water levels studied the meteorological elements that best correlated with the estimated reference evapotranspiration were relative humidity, solar radiation and wind speed, with values equal to $0.58,0.53$ and 0.49 , respectively.

Keywords: Irrigation management, Irrigameter coefficients, path analysis.

\footnotetext{
Recebido para publicação em 22/10/2014. Aprovado em 30/03/2015.

1 - Engenheiro Agrônomo, Professor Titular da UESB/Vitória da Conquista-BA, E-mail:tagliaferre@yahoo.com.br

2 - Engenheiro Florestal, Professor Adjunto da UESB/Vitória da Conquista-BA

3 - Engenheiro Agrícola, Professor IFBA/Vitória da Conquista-BA

4 - Mestrando em Meteorologia da UFV/Viçosa-MG

5 - Estudante do curso de Agronomia da UESB/Vitória da Conquista-BA.
} 


\section{INTRODUÇ̃̃O}

O Irrigâmetro é um aparelho evapopluviométrico desenvolvido na Universidade Federal de Viçosa para ser utilizado no manejo da irrigação, visando otimizar o uso da água na agricultura irrigada. A patente do aparelho está depositada no Instituto Nacional da Propriedade Industrial (INPI), em nome da Universidade Federal de Viçosa, sendo resultado de pesquisa desenvolvida no âmbito da universidade pública brasileira. $\mathrm{O}$ equipamento apresenta grande potencial de uso na agricultura irrigada, pois, além de ser um equipamento simples, de fácil manuseio, ele fornece resposta prática às duas perguntas básicas do manejo de irrigação: quando e quanto irrigar. Assim, o irrigante não precisa ter conhecimentos técnicos especializados sobre irrigação (OLIVEIRA et al., 2008). De acordo com os resultados obtidos por Oliveira et al. (2007a), Oliveira et al. (2007b), Tagliaferre et al. (2012) e Tagliaferre et al. (2014), o Irrigâmetro pode ser usado para estimar a evapotranspiração de qualquer cultura, em qualquer estádio de desenvolvimento, para um valor de Kc desejado. Sendo assim, o uso do Irrigâmetro torna-se uma alternativa viável por ser de custo mais baixo que o tanque Classe "A" e a estação meteorológica automática e, principalmente, por ser de fácil operação (OLIVEIRA et al., 2008).

A evapotranspiração é dependente dos elementos meteorológicos, do solo e da planta. De acordo com Penman (1956), quando a cobertura do solo é completa, a evapotranspiração é condicionada principalmente pelos elementos meteorológicos. Dentre esses elementos, o saldo de radiação é o que exerce maior influência na taxa de evapotranspiração dos cultivos. Villa Nova (1987) ressalta que é difícil separar a ação de cada um desses elementos, pois os mesmos agem simultaneamente. De maneira geral, quanto maior a disponibilidade de energia solar, maior a temperatura do ar e a velocidade do vento e, quanto menor a umidade relativa do ar, maior deverá ser a demanda evaporativa da atmosfera, ocasionando aumento na taxa de evapotranspiração, quando a umidade do solo não for fator restritivo.

Em condições de campo, os elementos meteorológicos atuam sobre a evapotranspiração de referência de forma interdependentes, dificultando o entendimento isolado do efeito de um ou outro elemento sobre a evapotranspiração estimada pelo
Irrigâmetro ou nos evaporímetros (CAIXETA, 2009). Segundo o autor (op. cit.), as investigações físicas evidenciam que a água perdida no processo de evapotranspiração em superfície vegetada e nos evaporímetros depende de três componentes do clima: o energético, o déficit de saturação de vapor de água e o transporte do vapor de água. Esses componentes não atuam separadamente na natureza, mas aparecem em várias combinações e efeitos recíprocos, interagindo e influenciando, de forma significativa, o processo da evapotranspiração nas diferentes condições climáticas.

O conhecimento do comportamento e das interações dos elementos meteorológicos sobre a evaporação e a evapotranspiração que ocorrem em evaporímetros é pouco relatado na literatura, principalmente, para equipamentos novos. Neste caso, o entendimento da correlação dos elementos meteorológicos sobre e a evapotranspiração estimada no Irrigâmetro possibilita verificar a necessidade ou não de se fazer ajustes na altura do evaporatório do aparelho em determinadas condições climáticas.

Silveira e Andrade (2002), trabalhando com a Análise de Componentes Principais (ACP) na investigação da estrutura multivariada da evapotranspição, no estado do Ceará, encontraram que, dentre as variáveis climatológicas estudadas, as que apresentaram maior peso no processo da evapotranspiração foram a razão de insolação $(\mathrm{n} / \mathrm{N})$ e a umidade relativa do ar (UR).

Para a região Centro Sul, e também no estado do Ceará, Andrade et al. (2003) revelaram que as variáveis climatológicas investigadas com maior representatividade no processo da evapotranspiração em região de clima semiárido foi a razão de insolação $(\mathrm{n} / \mathrm{N})$ e a precipitação (PPT), apresentando valores de correlações iguais a 0,$93 ;-0,82$, respectivamente.

Para entender melhor as associações entre diferentes variáveis, Wright (1921) propôs um método de desdobramento dos coeficientes de correlação. Esse método é denominado análise de trilha ou análise de caminhamento. A análise de trilha consiste no estudo dos efeitos diretos e indiretos de variáveis explicativas sobre uma variável básica, cujas estimativas são obtidas por meio de equações de regressão, constituindo-se numa expansão da regressão múltipla, em que as variáveis são previamente padronizadas.

A importância da correlação entre variáveis reside no fato de se poder avaliar quanto da 
alteração de uma variável pode afetar as demais, porém podem também ocorrer alguns equívocos quando da quantificação da magnitude das correlações entre as variáveis. A alta correlação entre duas variáveis pode ser o resultado de uma terceira sobre elas, ou de um grupo de variáveis (CRUZ; REGAZZI, 1997).

Diante do exposto, elevando-se em consideração que o equipamento é recém inventado, a busca de informações relativas sobre a influência e o entendimento das relações físicas dos elementos meteorológicos no processo da evapotranspiração em várias regiões do Brasil é fundamental. Sendo assim, objetivou-se com este trabalho analisar os efeitos das interações dos elementos meteorológicos, temperatura máxima e mínima do ar, umidade relativa do ar, velocidade do vento e radiação solar, na evapotranspiração de referência estimada pelo Irrigâmetro operando com diferentes alturas do nível de água no evaporatório.

\section{MATERIAL E MÉTODOS}

Para realização deste trabalho utilizaram-se dados obtidos de um experimento conduzido com Irrigâmetros na área experimental do Instituto Federal da Bahia (IFBA), localizado no município de Guanambi - BA, situado nas coordenadas $14^{\circ}$ 13' 30"de latitude Sul, $42^{\circ} 46^{\prime}$ '53" de longitude Oeste e com altitude de $525 \mathrm{~m}$, durante o período de abril de 2009 a janeiro de 2010. O clima da região é classificado como semiárido $(\mathrm{BSa})$ pela classificação de Köppen, apresentando temperatura média anual de $22,6{ }^{\circ} \mathrm{C}$ e precipitação média de $715 \mathrm{~mm} \mathrm{ano}^{-1}$.

A determinação dos efeitos das variáveis meteorológicas na evapotranspiração estimada pelo Irrigâmetro foi feita com o aparelho operando com diferentes níveis de água no evaporatório. Para isso, o experimento foi montado num delineamento inteiramente casualizado, com sete tratamentos e três repetições. Foram instalados 21 Irrigâmetros dispostos lado a lado, espaçados de 3,5 por 3,5 m para evitar sombreamento nos evaporatórios. Os tratamentos consistiram de Irrigâmetros operando com as seguintes alturas do nível de água no evaporatório: $\mathrm{N}_{1}=1, \mathrm{~N}_{2}=2, \mathrm{~N}_{3}=3, \mathrm{~N}_{4}=4, \mathrm{~N}_{5}=$ $5, \mathrm{~N}_{6}=6$ e $\mathrm{N}_{7}=7 \mathrm{~cm}$, tomadas a partir de um nível de referência próprio do equipamento.

Para estudar os efeitos das variáveis meteorológicas na evapotranspiração de referência estimada pelo Irrigâmetro, utilizou-se a análise de trilha (path analysis). A técnica da estatística multivariada, como a análise de trilha, possibilita realçar os efeitos diretos e indiretos de um conjunto de variáveis climáticas sobre uma variável principal. Neste caso, pode-se aplicá-la para verificar a importância de um ou mais elementos meteorológicos na evapotranspiração estimada no Irrigâmetro. Assim, os coeficientes de trilha (efeito direto) podem ser comparados entre si e com o efeito da variável residual, que é utilizado como referencial para a importância do efeito direto da variável explicativa sobre a variável principal. Quando o coeficiente de trilha (efeito direto) de uma variável explicativa for, em módulo, menor que o coeficiente da variável residual, mas o coeficiente de determinação (efeito total) for maior que o efeito da variável residual, isso significa que essa variável explicativa influencia a variável principal apenas indiretamente, sendo sua importância só em conjunto. Se o coeficiente de trilha for, em módulo, maior que o coeficiente da variável residual, ele indica que existe efeito direto da variável explicativa sobre a principal.

$\mathrm{Na}$ Figura 1 está apresentado o diagrama utilizado para a melhor interpretação dos resultados da análise de trilha, que desdobra os coeficientes de Pearson em efeitos diretos e indiretos.

Conforme sugerido por Cruz e Regazzi (1997), realizou-se a avaliação de multicolinearidade a partir das matrizes dos coeficientes de correlação. As variáveis explicativas foram previamente escolhidas, tendo sido feito, inicialmente, a análise de correlação linear simples (correlação de Pearson), utilizando o programa estatístico GENES 2007.0.0 (Análise de Métodos Biométricos Aplicados à Genética Quantitativa Estatística Experimental), para obter as matrizes de correlação e suas significâncias pelo teste “t”, em níveis de 1\% e $5 \%$ de probabilidades. Posteriormente, foi feita a análise de trilha com o objetivo de estimar as correlações e analisar a relação entre as variáveis explicativas, temperatura máxima e mínima do ar, umidade relativa do ar, velocidade do vento e radiação solar pelos seus desdobramentos em efeitos diretos e indiretos sobre a variável principal, no caso a evapotranspiração estimada pelos Irrigâmetros.

\section{RESULTADOS E DISCUSSÃO}

Nas Figuras 2 e 3 encontram-se apresentados os valores médios diários da temperatura máxima 


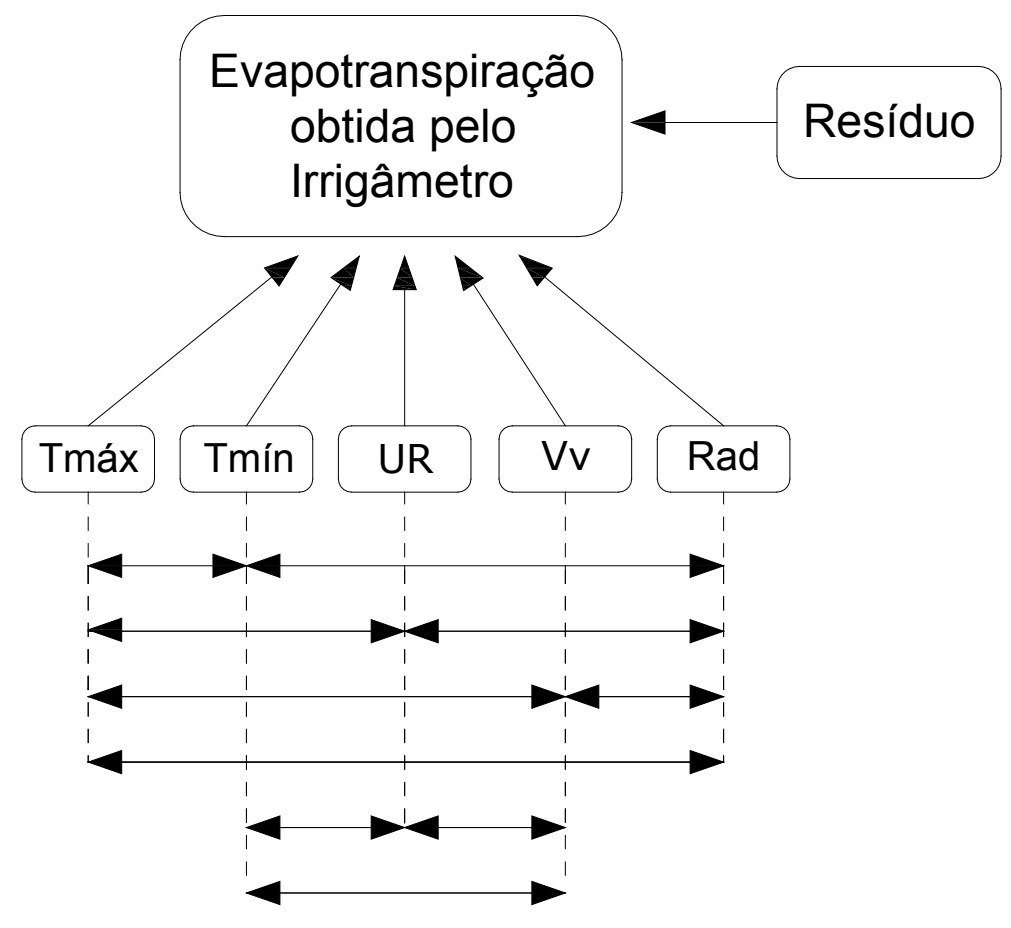

Obs: As setas unidirecionais indicam o efeito direto de uma variável explicativa sobre a principal, enquanto as setas bidirecionais representam a interdependência de duas variáveis explicativas e determinam a trilha representativa do efeito indireto sobre a variável básica.

Figura 1. Diagrama causal indicando a interrelação das variáveis explicativas: Tmáx = temperatura máxima do ar; Tmín = temperatura mínima do ar; $\mathrm{UR}=$ umidade relativa do ar; $\mathrm{Vv}=$ velocidade do vento; e Rad = radiação sobre a variável principal, a evapotranspiração obtida pelo Irrigâmetro.

e mínima do ar, da umidade relativa do ar, da velocidade do vento e da radiação solar utilizado na estimativa da evapotranspiração de referência, obtidos durante o período experimental.

Medeiros (2002), Valero e Mañas (1993) e Chang, (1971) relataram que os principais elementos meteorológicos que proporcionam energia para evaporação e remoção de vapor de água, a partir de superfícies evaporantes, são a radiação solar, a temperatura do ar, a umidade relativa e a velocidade do vento, além do déficit de pressão de vapor. A radiação solar é o elemento de maior importância na demanda evaporativa da atmosfera. Entretanto, a influência isolada dos elementos climáticos na evaporação de superfícies água-livre, como nos tanques evaporimétricos, é difícil de ser quantificada. Hounam (1973) cita que a evaporação da água em tanques não é função apenas das condições climáticas durante determinado período, mas também das características do reservatório e do calor advectivo provenientes de áreas secas adjacentes. Essas características se inter-relacionam com as condições climáticas, dificultando a medição da sua influência na evaporação.

Durante o período experimental observou-se uma grande amplitude dos valores de umidade relativa do ar, sendo que a média diária foi em grande parte do período experimental superior a $58 \%$, classificada como média; com a ocorrência de valores extremos, sendo 42 e $86 \%$ os valores mínimo e máximo, respectivamente. Valores mais altos de umidade relativa do ar foram observados nos meses de março até junho. Com relação à temperatura média do ar o seu valor ficou em torno de $26{ }^{\circ} \mathrm{C}$, sendo observados valores máximo e mínimo de $36,5^{\circ} \mathrm{C}$ e $17^{\circ} \mathrm{C}$, respectivamente. A velocidade média do vento foi superior a $3 \mathrm{~m} \mathrm{~s}^{-1}$, considerada moderada, de acordo com Doorenbos e Pruitt (1977), variando de 0,5 a $7 \mathrm{~m} \mathrm{~s}^{-1}$. A radiação solar média diária do período em estudo foi de $223,6 \mathrm{~W} \mathrm{~m}^{-2}$.

\section{REVENG




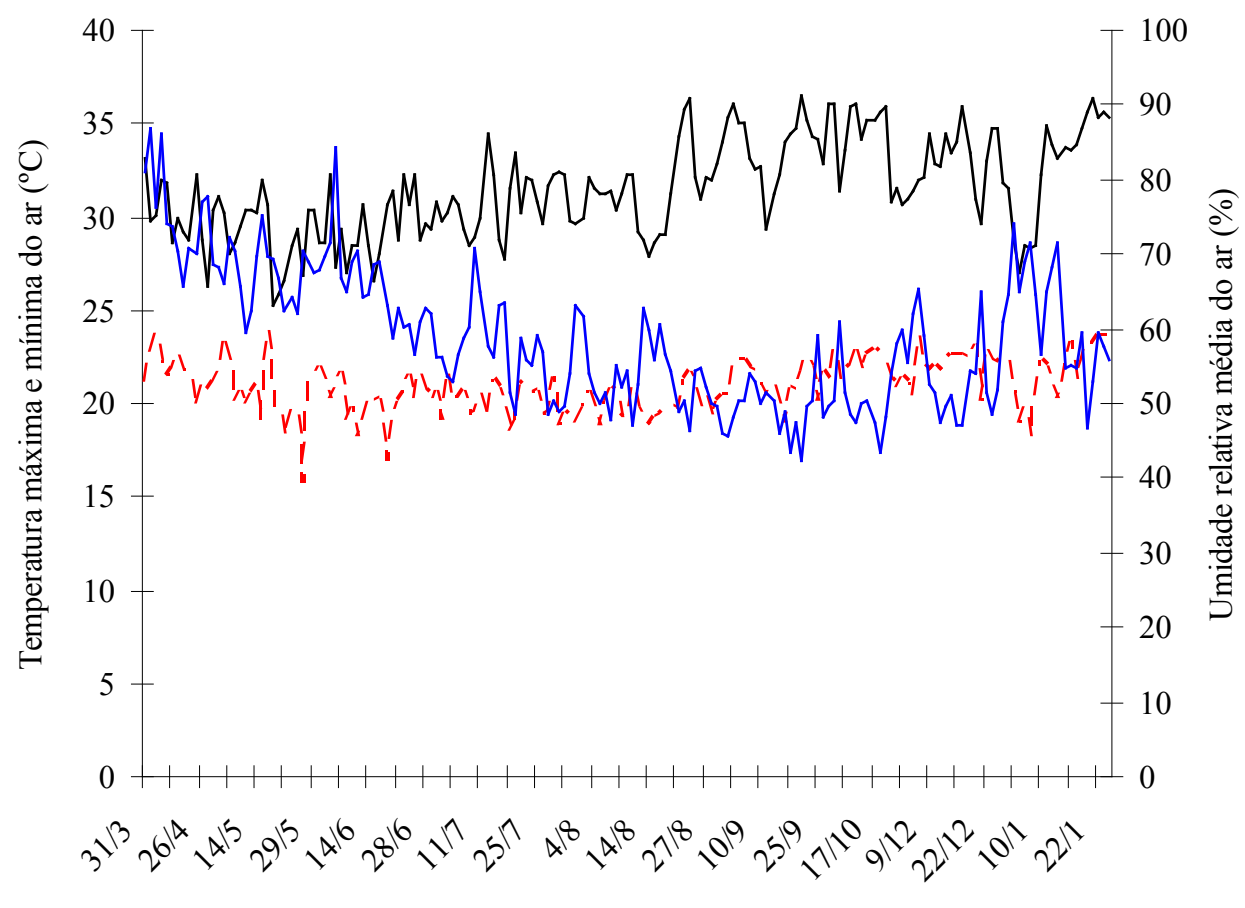

Dias do ano

— Temp. máxima ---- Temp. mínima — Umidade relativa

Figura 2. Variação diária da temperatura máxima e mínima do ar e umidade relativa do ar durante o período experimental.

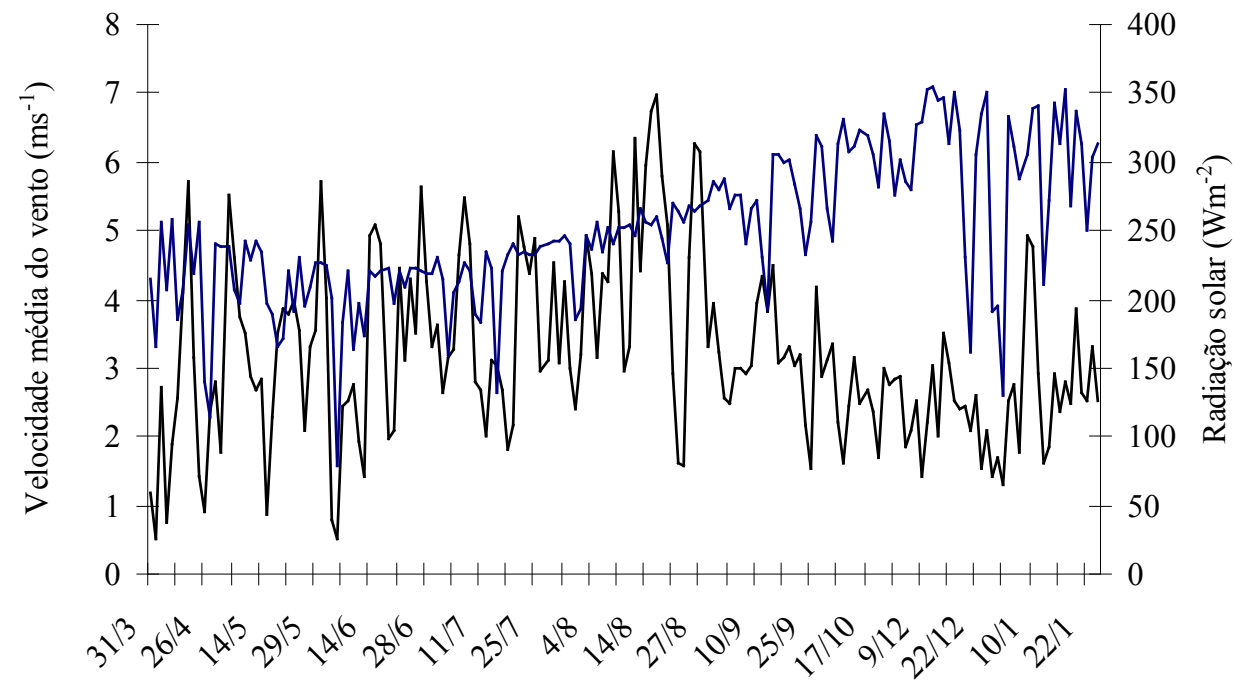

Dias do ano

— Velocidade do vento — Radiação solar

Figura 3. Variação diária da velocidade média do vento e da radiação solar ao longo do período experimental. 
Na Figura 4 estão apresentados os valores da evapotranspiração estimada no Irrigâmetro em função dos diferentes níveis de água no interior do evaporatório para todo o período experimental.

Observa-se que a evapotranspiração estimada com o Irrigâmetro aumentou exponencialmente com o nível da água dentro do evaporatório. Quando o nível da água se encontra próximo à superfície, ocorre maior interceptação da radiação solar, variável que apresenta maior influência no processo de evaporação (CHANG, 1971), ao mesmo tempo em que favorece a ação do vento, atuando na remoção do ar saturado sobre a superfície evaporante. Ao contrário, quando o nível da água se encontra mais distante da borda do evaporatório, aumenta o sombreamento da água contida no seu interior, em certas horas do dia, resultando em menor evaporação.
O ótimo ajuste do modelo aos dados obtidos indica que a equação de regressão pode ser utilizada para determinar os níveis de água no evaporatório do Irrigâmetro para obter diretamente a evapotranspiração de referência ou da cultura para qualquer estádio de desenvolvimento. Os resultados obtidos por Tagliaferre et al. (2012) para a localidade de Guanambi-Ba indicam que o Irrigâmtero deve operar com nível de água no interior do seu evaporatório igual a $3,5 \mathrm{~cm}$ para estimar diretamente a evpotranspiração de referência.

Nos Quadros 1 e 2 estão apresentados os valores dos coeficientes de correlação de Pearson entre as variáveis explicativas para a evapotranspiração estimada pelo Irrigâmetro para todo período experimental.

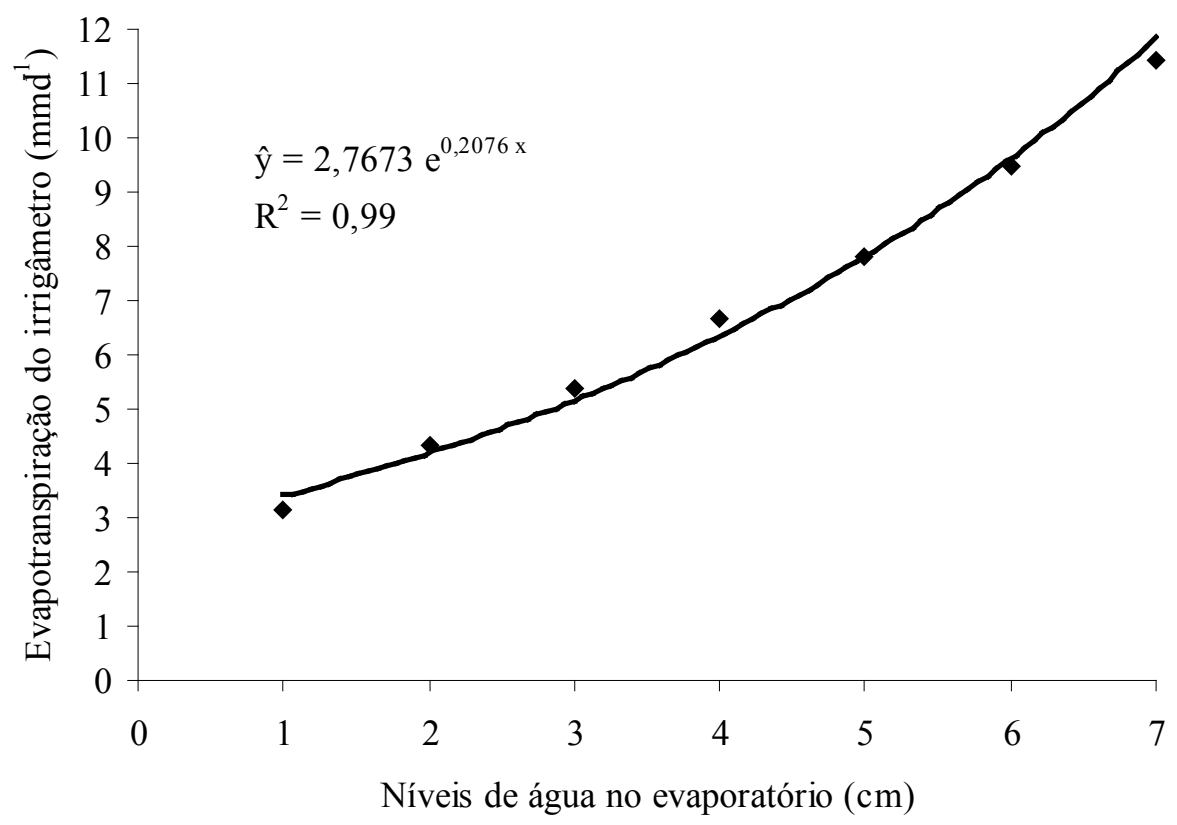

Figura 4. Relação entre a evapotranspiração estimada pelo Irrigâmetro e os níveis de água dentro do evaporatório para todo o período experimental.

Quadro 1. Estimativa dos coeficientes de correlação de Pearson entre as variáveis explicativas para a evapotranspiração estimada pelo Irrigâmetro para todo período experimental.

\begin{tabular}{ccccc}
\hline & T mín & UR & Vv & Rad \\
\hline T max & $0,5010^{* *}$ & $-0,6356^{* *}$ & $-0,3083^{* *}$ & $0,6235^{* *}$ \\
T mín & & $-0,1148 \mathrm{~ns}$ & $-0,1440^{*}$ & $0,3319^{* *}$ \\
UR & & $-0,2121^{* *}$ & $-0,6017^{* *}$ \\
Vv & & & $0,0389 \mathrm{~ns}$ \\
\hline
\end{tabular}

ns Não-significativo a $5 \%$ pelo teste t; * Significativo a $5 \%$, pelo teste t; $* *$ Significativo a $1 \%$, pelo teste $t$. 
Os elementos meteorológicos temperatura máxima e mínima do ar, umidade relativa do ar e radiação apresentaram correlação significativa entre si, como já era de ser esperado. Apenas a umidade relativa com temperatura mínima e a velocidade do vento com a radiação solar apresentaram correlação não significativa pelo teste $t$.

Para verificar a influência de cada elemento meteorológico sobre a evapotranspiração desdobraram-se por meio da análise de trilha, as correlações de cada variável independente (temperatura máxima - Tmax, temperatura mínima - Tmin, umidade relativa - UR, velocidade do vento - Vv e radiação - Rad) com a variável dependente (evapotranspiração) estimada pelo Irrigâmetro, para o período diário, em seus efeitos diretos e indiretos. Os resultados obtidos da análise de trilha estão apresentados no Quadro 2.

Observa-se no Quadro 2 que o ajuste dos dados para explicar a influência dos elementos meteorológicos sobre a estimativa da evapotranspiração pelo Irrigâmetro permaneceu constante à medida que o nível da água aumentou de 1 para $7 \mathrm{~cm}$ e que as correlações foram significativas pelo teste t a $1 \%$ de significância em todos dos níveis de água no evaporatório do Irrigâmetro. Sendo assim, pode-se afirmar que esses elementos meteorológicos influenciam em menor ou em maior grau a evapotranspiração obtida no Irrigâmetro.

Pode-se notar que, em todos os níveis de água no evaporatório, os elementos meteorológicos que apresentaram maior correlação com a evapotranspiração estimada pelo Irrigâmetro foi umidade relativa do ar, velocidade do vento e radiação. Ressalta-se neste estudo que a velocidade do vento apresentou um grande efeito na evapotranspiração estimada no Irrigâmetro, em virtude da região apresentar ventos com velocidade moderada em grande parte do ano, conforme se observa na Figura 3. Resultados divergentes foram obtidos por Caixeta (2009) e Oliveira et al. (2011). Com relação à umidade relativa e a radiação, os resultados obtidos corroboram com os obtidos por Giovanelli (2012), que encontrou valores de correlação total iguais a 0,89 e 0,73 , respectivamente, para algumas estações do ano, durante os anos de 2008 a 2011. Silveira e Andrade
(2002) encontraram que, dentre as variáveis meteorológicas estudadas, as que apresentam maior peso no processo da evapotranspiração foram insolação e umidade relativa do ar. Já Andrade et al. (2003) constataram que as variáveis meteorológicas investigadas com maior representatividade no processo da evapotranspiração foram insolação e velocidade do vento, enquanto as temperaturas máxima e mínima do ar apresentaram menor influência.

As estimativas dos efeitos diretos elevados e de sinais iguais aos dos coeficientes de correlação total, indicaram que a umidade relativa, a velocidade do vento, a radiação e, em menor grau, a temperatura máxima foram as principais variáveis na decomposição da evapotranspiração estimada pelo Irrigâmetro. Isso mostra que a variações desses elementos meteorológicos provocam mudanças diretas na evapotranspiração estimada pelo Irrigâmetro, caracterizando esses elementos meteorológicos como os principais na tentativa de explicar a variável dependente.

Os efeitos indiretos da variável temperatura máxima e umidade relativa do ar via radiação se destacaram como os mais associados na tentativa de explicar a evapotranspiração em todos os níveis de água no evaporatório do Irrigâmetro, pois apresentaram os maiores valores de correlação, variando de 0,12 a 0,22 .

Em estudo realizado na região de ViçosaMG, Caixeta (2009) observou que o efeito indireto da variável temperatura máxima via radiação destacou-se como o mais associado à evapotranspiração em todos os níveis de água no evaporatório do Irrigâmetro. De acordo com o mesmo autor, houve relação direta entre a variável dependente evapotranspiração estimada pelo Irrigâmetro e a variável explicativa temperatura máxima. $\mathrm{O}$ efeito indireto da temperatura máxima via radiação foi elevado, tendo sido correlacionado de 0,36 a 0,39 , enquanto que a umidade relativa do ar de 0,31 a 0,34 .

Amorim (1998), estudando as ligações da evapotranspiração com os elementos climáticos no município de Governador Dix-Sept Rosado, situado na região agrícola de Mossoró-RN, observou que a insolação foi o elemento meteorológico de maior influência no processo de evapotranspiração de 
Quadro 2. Estimativa dos efeitos diretos e indiretos e correlação total entre a variável evapotranspiração obtida no Irrigâmetro e as variáveis temperatura máxima, temperatura mínima, umidade relativa, velocidade do vento e radiação para cada nível de água e para todo período experimental

\begin{tabular}{|c|c|c|c|c|c|c|c|}
\hline Temperatura máxima doa ar & Nível 1 & Nível 2 & Nível 3 & Nível 4 & Nível 5 & Nível 6 & Nível 7 \\
\hline Direto sobre ET & 0,264 & 0,269 & 0,267 & 0,249 & 0,320 & 0,244 & 0,195 \\
\hline Indireto via T mín & $-0,018$ & $-0,013$ & $-0,023$ & $-0,009$ & $-0,023$ & $-0,001$ & 0,031 \\
\hline Indireto via Ur & 0,068 & 0,072 & 0,118 & 0,091 & 0,105 & 0,099 & 0,119 \\
\hline Indireto via $\mathrm{Vv}$ & $-0,150$ & $-0,166$ & $-0,156$ & $-0,166$ & $-0,159$ & $-0,165$ & $-0,173$ \\
\hline Indireto via Rad & $-0,223$ & 0,182 & 0,160 & 0,160 & 0,149 & 0,135 & 0,119 \\
\hline Total (cor. Pearson) & $0,387 *$ & $0,346^{*}$ & $0,365^{*}$ & $0,325^{*}$ & $0,391^{*}$ & $0,312 *$ & $0,291^{*}$ \\
\hline \multicolumn{8}{|l|}{ Temperatura mínima do ar } \\
\hline Direto sobre ET & $-0,036$ & $-0,025$ & $-0,046$ & $-0,019$ & $-0,046$ & $-0,001$ & 0,061 \\
\hline Indireto via T Max & 0,132 & 0,135 & 0,133 & 0,125 & 0,160 & 0,122 & 0,098 \\
\hline Indireto via Ur & 0,012 & 0,013 & 0,021 & 0,016 & 0,019 & 0,018 & 0,022 \\
\hline Indireto via $\mathrm{Vv}$ & $-0,070$ & $-0,077$ & $-0,073$ & $-0,077$ & $-0,074$ & $-0,077$ & $-0,081$ \\
\hline Indireto via Rad & 0,119 & 0,097 & 0,085 & 0,085 & 0,079 & 0,072 & 0,064 \\
\hline Total (cor. Pearson) & $0,157^{* *}$ & $0,142 *$ & $0,121 *$ & $0,131 * *$ & $0,139 * *$ & $0,134 * *$ & $0,163 * *$ \\
\hline \multicolumn{8}{|l|}{ Umidade relativa do ar } \\
\hline Direto sobre ET & $-0,107$ & $-0,114$ & $-0,186$ & $-0,142$ & $-0,165$ & $-0,157$ & $-0,188$ \\
\hline Indireto via T Max & $-0,168$ & $-0,171$ & $-0,169$ & $-0,159$ & $-0,203$ & $-0,155$ & $-0,124$ \\
\hline Indireto via T mín & 0,004 & 0,003 & 0,005 & 0,002 & 0,005 & 0,001 & $-0,007$ \\
\hline Indireto via $\mathrm{Vv}$ & $-0,103$ & $-0,114$ & $-0,107$ & $-0,114$ & $-0,109$ & $-0,114$ & $-0,119$ \\
\hline Indireto via Rad & $-0,216$ & $-0,176$ & $-0,154$ & $-0,154$ & $-0,144$ & $-0,130$ & $-0,115$ \\
\hline Total (cor. Pearson) & $-0,589^{*}$ & $-0,572 *$ & $-0,612^{*}$ & $-0,568^{*}$ & $-0,616^{*}$ & $-0,556^{*}$ & $-0,553 *$ \\
\hline \multicolumn{8}{|l|}{ Velocidade do vento } \\
\hline Direto sobre ET & $-0,487$ & 0,537 & 0,507 & 0,538 & 0,517 & 0,537 & 0,561 \\
\hline Indireto via $\mathrm{T}$ Max & $-0,081$ & $-0,083$ & $-0,082$ & $-0,077$ & $-0,099$ & $-0,075$ & $-0,060$ \\
\hline Indireto via T mín & 0,005 & 0,004 & 0,007 & 0,003 & 0,007 & 0,001 & $-0,009$ \\
\hline Indireto via Ur & $-0,023$ & 0,024 & 0,039 & 0,030 & 0,035 & 0,033 & 0,039 \\
\hline Indireto via Rad & 0,014 & 0,011 & 0,010 & 0,010 & 0,009 & 0,008 & 0,007 \\
\hline Total (cor. Pearson) & $-0,447^{*}$ & $0,493 *$ & $0,481 *$ & $0,504^{*}$ & $0,469 *$ & $0,504 *$ & $0,539 *$ \\
\hline \multicolumn{8}{|l|}{ Radiação solar } \\
\hline Direto sobre ET & 0,358 & 0,292 & 0,256 & 0,257 & 0,239 & 0,217 & 0,192 \\
\hline Indireto via T Max & $-0,165$ & 0,168 & 0,166 & 0,156 & 0,199 & 0,152 & 0,121 \\
\hline Indireto via T mín & $-0,012$ & $-0,008$ & $-0,015$ & $-0,006$ & $-0,015$ & $-0,001$ & 0,020 \\
\hline Indireto via Ur & 0,064 & 0,069 & 0,122 & 0,086 & 0,099 & 0,094 & 0,113 \\
\hline Indireto via Vv & 0,019 & 0,021 & 0,020 & 0,021 & 0,020 & 0,021 & 0,022 \\
\hline Total (cor. Pearson) & $0,594 *$ & $0,542 *$ & $0,539 *$ & $0,513 *$ & $0,542 *$ & $0,484^{*}$ & $0,468^{*}$ \\
\hline Coef Determinação & 0,59 & 0,58 & 0,59 & 0,56 & 0,59 & 0,54 & 0,56 \\
\hline Ef. variável residual & 0,64 & 0,65 & 0,64 & 0,66 & 0,64 & 0,68 & 0,66 \\
\hline
\end{tabular}

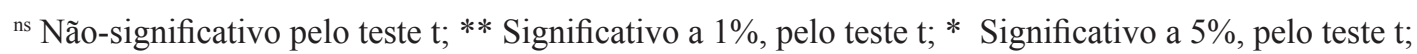


referência diária e a temperatura média compensada foi o elemento que apresentou menor efeito no processo, apresentando valores de correlações iguais a 0,51 e 0,15 , respectivamente.

\section{CONCLUSÕES}

- A evapotranspiração da água no interior do reservatório do Irrigâmetro aumentou exponencialmente com a elevação do nível da água;

- Em todos os níveis de água estudado o elemento meteorológico que apresentou maior correlação com a estimativa da evapotranspiração, em ordem decrescente, foi a umidade relativa do ar, a radiação solar, a velocidade do vento e a temperatura máxima e mínima do ar;

- O efeito indireto das variáveis temperatura máxima e umidade relativa do ar, via radiação, se destacaram como o mais associado, na tentativa de explicar a evapotranspiração estimada com o uso do Irrigâmetro.

\section{AGRADECIMENTOS}

Ao Banco do Nordeste do Brasil (BNB) pelo financiamento da pesquisa, ao Instituto Federal da Bahia de Guanambi (IFBA) pela disponibilização da área experimental e a Universidade Estadual Sudoeste da Bahia pela disponibilização de veículos.

\section{REFERENCIAS BIBLIOGRÁFICAS}

AMORIM, M.C. Avaliação da eficácia do lisímetro de lençol freático constante, do tanque classe "A" e do modelo de Penman-Monteith (FAO) para estimativa da evapotranspiração de referência(ET0). 1998.56f. Dissertação(Mestrado em Meteorologia Agrícola) - Universidade Federal de Viçosa, Viçosa, MG.

ANDRADE, E.M. de; SILVEIRA, S.S.; AZEVEDO, B.M. de. Investigação da estrutura multivariada da evapotranspiração na região centro sul do Ceará pela análise de componentes principais. Revista Brasileira de Recursos
Hídricos, Porto Alegre, v.8, n.1, p.39-44, 2003.

CAIXETA, S.P. Efeitos de elementos meteorológicos na evapotranspiração estimada pelo Irrigâmetro nas condições climáticas da zona da mata mineira. 2009. 51f. Dissertação (Mestrado em Meteorologia Agrícola) Universidade Federal de Viçosa, Viçosa, MG.

CHANG, J. Climate and Agriculture. Chicago: Aldine Publishing, 1971. 296p.

CRUZ, C.D.; REGAZZI, A.J. Modelos biométricos aplicados ao melhoramento genético. 2. ed. Viçosa, MG: UFV, 1997. 390p.

DOORENBOS, J.; PRUITT, J.O. Crop water requeriment. Rome: FAO, 1977. 144p. (FAO Irrigation and Drainage Paper, 24).

GENES. Programa para análise e processamento de dados baseado em modelos de genética e estatística experimental. Versão 2007.0.0: Fundação Arthur Bernardes-UFV: Viçosa, 2007.

HOUNAM, C.E. Comparison between pan and lake evaporation. Geneva: World Meteorological Organization, 1973. 52p. (Tech. Note, 126; WMO, 354).

MEDEIROS, A.T. Estimativa da evapotranspiração de referência a partir da equação de Penman-Monteith, de medidas lisimétricas e de equações empíricas, em Paraipaba, CE. 2002. 103f. Tese (Doutorado em Agronomia) - Escola Superior de Agricultura Luiz de Queiroz, Piracicaba, SP.

OLIVEIRA, E.M. de; OLIVEIRA, R.A. de; SEDIYAMA, G.C.; CECON, P.R.; DRUMOND, L.C.D. Análise do coeficiente e o desempenho do Irrigâmetro e a influência dos elementos do clima na estimativa da evapotranspiração. Revista Engenharia na Agricultura, Viçosa, v.19, n.4, p.348-360, 2011.

OLIVEIRA, E.M. de; OLIVEIRA, R.A. de; BAPTESTINI, J.C.M. Ajuste do Irrigâmetro para 
estimar a evapotranspiração da cultura, por meio da variação da área do evaporatório. In: SIMPÓSIO DE INICIAÇÃO CIENTÍFICA, 12, Viçosa, MG, 2007a Anais... Viçosa, MG: UFV, 2007a. 1 CDROM.

OLIVEIRA, E.M. de; OLIVEIRA, R.A. de; BAPTESTINI, J.C.M. Ajuste do Irrigâmetro para estimar a evapotranspiração da cultura nos seus diversos estádios de desenvolvimento. In: CONGRESSO NACIONAL DE ENGENHARIA AGRÍCOLA, 36, Bonito, MS, 2007 Anais... Bonito, MS: SBEA, 2007b. 1 CD-ROM.

OLIVEIRA, R.A.; TAGLIAFERRE, C.; SEDIYAMA, G.C.; MATERAN, F.J.V.; CECON, P.R. Desempenho do Irrigâmetro na estimativa da evapotranspiração de referência. Revista Brasileira de Engenharia Agrícola e Ambiental, Campina Grande, v.12, n.2, p.166-173, 2008.

PENMAN, H.I. Evaporation: an introductory survey. Netherlands. Journal of Agricultural Science, Cambridge, v.4, p.9-29, 1956.

SILVEIRA, S.S.; ANDRADE, E.M. de. Análise de componentes principais na investigação de estrutura multivariada da evapotranspiração. Engenharia Agrícola, Jaboticabal, v.22, n.2, p.173-177, 2002.

TAGLIAFERRE, C.; SANTOS NETO, I.J. dos; COTRIM, C.E.; ROCHA, F. A.; SANTOS, L.C. Desempenho do Irrigâmetro e de métodos de estimativa da evapotranspiração de referência para o município de Guanambi-BA. Revista Engenharia na Agricultura, Viçosa, v.20, n.6, p.544-553, 2012.

TAGLIAFERRE, C.; SANTOS, L. da C.; SANTOS NETO, I.J. dos; SANTOS, T.J.; ROCHA, F.A.; GUIMARÃES, D.U. Estimativa da evapotranspiração de referência com uso do Irrigâmetro em Vitória da Conquista-BA. Revista Irriga, v. 17, p.28-38, 2012.

TAGLIAFERRE, C.; SANTOS, L. da C.; SANTOS NETO, I.J. dos ; SANTOS, T.J.; ROCHA, F.A.; SILVA, C.S. Ajuste e aplicação do Irrigâmetro no manejo da água de irrigação. Revista Irriga, UNESP, v.19, p.61-72, 2014.

VALERO, J.A. de J.; MAÑAS, F.J.M. de S.O. El calculo y la estimacion de la evapotranspiracion. In: MAÑAS, F.J. M. de S.O.; VALERO, J.A. de J. Agronomia del riego. Madrid: Mundi-Prensa, 1993. p. 373-446.

VILLA NOVA, N.A. Principais métodos de estimativa de aplicação de água de irrigação. Piracicaba: Departamento de Física e Meteorologia, ESALQ/USP, 1987. 22p.

WRIGTH, S. Correlation and causation. Journal of Agricultural Research, Washington, v.20, 1921. 